\title{
Anomalous crustal movements with low seismic efficiency - Campi Flegrei, Italy and some examples in Japan
}

\author{
Izumi Yokoyama $\left({ }^{1}\right)$ and Antonio Nazzaro $\left({ }^{2}\right)$ \\ ( ${ }^{1}$ Higashi 1-17-7-1304, Kunitachi, Tokyo, Japan \\ (2) Viale Italia 419, Avellino, Italy
}

\begin{abstract}
Campi Flegrei is a unique volcanic region located near Naples, Italy. Anomalous crustal movements at Pozzuoli in Campi Flegrei have been documented since the Roman period. The movements were gradual and have continued to the present, occasionally accompanying swarms of local earthquakes and volcanic eruptions. Generally the movements proceed with low seismicity. After the 1538 eruption of Monte Nuovo, Pozzuoli had subsided monotonously, but it changed to uplift abruptly in 1969. The uplift accelerated in 1983 and 1984 reaching more than $2 \mathrm{~m}$, and thereafter began to subside. Many discussions of this event have been published. In Japan, we have examples of deformations similar to those at Campi Flegrei, mainly in volcanic areas, and rarely in non-volcanic areas. The former includes Iwojima, Miyakejima and Aira caldera while the latter is represented by Cape Omaezaki. Iwojima is a volcano island, and its secular uplifts since the 18th century are recognized as an unusual event. Miyakejima volcano and Aira caldera exhibited anomalous movements with low seismicity after their eruptions. Cape Omaezaki is not situated in volcanic zone but near a subduction zone, and gradually and continuously subsides as a precursor to a large earthquake. In such cases as Campi Flegrei and the Japanese localities, we would question whether the deformations are accompanied by normal seismicity or low seismicity. To examine quantitatively the relationship between seismicity and related deformation, seismic efficiency is generally useful. The crustal deformations in all the regions cited above are characterized by exceptionally low seismic efficiencies. In the present paper, the deformations at Pozzuoli and Iwojima are mainly described and a comparative discussion among these and other localities in Japan is supplemented. It is concluded that such anomalous phenomena in volcanic areas are attributable to peculiar rheological aspects of the material composing the local upper crust, and the deformation in a non-volcanic area is of tectonic origin.
\end{abstract}

Key words crustal movements - low seismic efficiency - Campi Flegrei - Iwojima - Aira caldera Miyakejima - Cape Omaezaki

\section{Introduction}

We know many examples of ground deformation accompanying major earthquakes: they usually appear instantaneously with the

Mailing address: Dr. Izumi Yokoyama, Higashi 1-177-1304 Kunitachi, Tokyo 186-0002 Japan; e-mail: iyokoya@aol.com earthquakes, and often accompany the formation of faults and fractures. On the other hand, there are a few examples of secular ground deformations with very low seismicity. In Italy, these are called «Bradisismi» (slow movements), often observed along shores. Serapeo, the ruins of a Roman market place at Pozzuoli being located at the shore of Campi Flegrei, has been used as a benchmark for sea level changes for 20 centuries. The anomalous uplifts since 1969 centering on Pozzuoli were remarkable and are called the Pozzuoli event. In Japan, secular ground movements are usually related to volcanic activities such as Iwojima, Aira caldera 
and Miyakejima volcano. In addition, there is one of slow movement in non-volcanic area: Cape Omaezaki in the Tokai district has subsided secularly since the first survey in 1962 , and the subsidence is one of the precursors of a large subduction earthquake. In the following, the activities of Campi Flegrei and Iwojima are briefly described mainly on basis of the published data, and then some similar examples of anomalous deformations such as Aira caldera, Miyakejima volcano and Cape Omaezaki, are mentioned. To examine quantitatively the relationship between seismicity and related deformation, seismic efficiencies of some earthquakes are estimated. In the closing section of this paper, their characteristics are comparatively discussed mainly from a standpoint of their origins. In the present paper, gradual ground deformations are limited to vertical ones.

\section{Campi Flegrei}

Campi Flegrei is a caldera measuring $15 \mathrm{~km}$ in diameter and consists of multiple phreatic craters, monogenetic cones and fumaroles. A topographic sketch map of Campi Flegrei is shown in fig. 1 where the southern half of the caldera is bounded by three shallow banks in Pozzuoli Bay. The town of Pozzuoli is located near the center of the Flegrean caldera and has been populated since the Roman period.

\subsection{Geologic setting of Campi Flegrei}

Campi Flegrei caldera was formed approximately 35000 years B.P. by the eruption of $80 \mathrm{~km}^{3}$ of the Campanian tuff (Rosi et al., 1983). Judged from the Bouguer gravity anomalies there, the caldera is funnel-shaped and its center coincides with the town of Pozzuoli. The caldera fill is the tuff and the fall-back which have lower density than the basement rocks (carbonatic and/or thermometamorphic rocks). According to Fedi et al. (1991), the low density material $(\Delta \rho=-200 \mathrm{~kg} /$ $\mathrm{m}^{3}$ ) fills the caldera to a depth of approximately $2 \mathrm{~km}$ at the center.

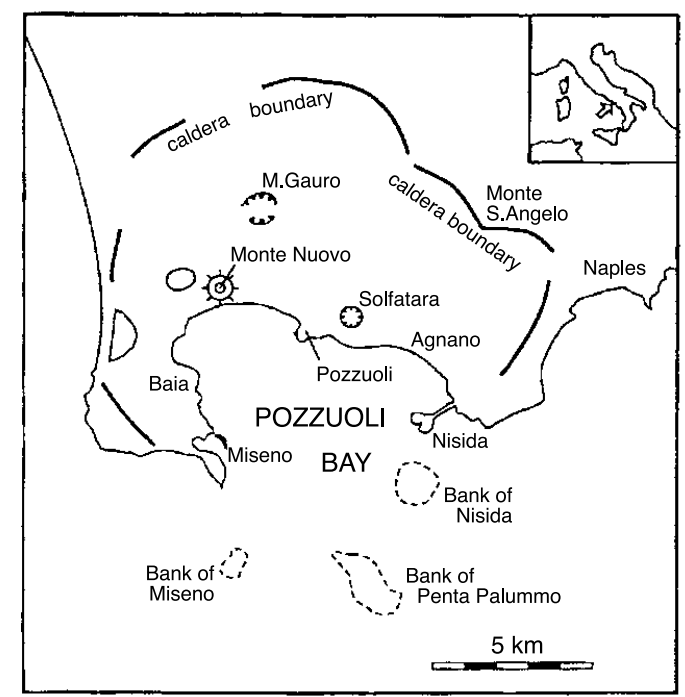

Fig. 1. Topographic sketch map of Campi Flegrei (after Dvorak and Gasparini, 1991).

\subsection{Ground deformations and seismicity at Pozzuoli}

Anomalous upheaval since 1969 centering on Pozzuoli in a densely populated area attracted interest of earth scientists all over the world. This is called the Pozzuoli event (Yokoyama, 1970). Many research papers were published on this event: the special issues of Bulletin Volcanologique, vol. 47 (1984, Eds. F. Barberi, D. Hill, F. Innocenti, G. Luongo and M. Treuil) and Journal of Volcanology and Geothermal Research, vol. 48 (1991, Eds. G. Luongo and R. Scandone) are devoted to the events in Campi Flegrei, including 20 and 15 papers, respectively. In the present paper, we owe various pieces of information and interpretation of the Pozzuoli event to these papers.

The height above sea level of Serapeo at Pozzuoli has been documented from time to time since the Roman period. Actually it may be rather difficult to establish the trend of deformation at Serapeo, especially during the ancient periods. Parascandola (1947) proposed the secular vertical deformation at Serapeo as shown in fig. 2a where we can infer a relationship between the 
deformation and large eruptions of Vesuvius. Actually the areas are connected through an underwater tectonic structure (Nazzaro, 1985). Serapeo subsided monotonously for approximately 9 centuries since the Roman period, with the exception of short periods of uplift related to the 79 eruption of Vesuvius and one other eruption. In the 10th century, the pattern changed to uplift and sharply rose in case of the 1538 eruption of Monte Nuovo. After 1538, it again subsided till 1969. According to Dvorak and Gasparini (1991), it is probable that no uplift larger than a few meters occurred during the period between 1538 and the 1820's when the sea level measurements near Pozzuoli were made for the first time. Serapeo subsided at an average rate of $1.4 \mathrm{~cm} / \mathrm{yr}$ between 1820's and 1969. In 1969 , it began to rise suddenly probably due to magma or steam intrusion beneath Campi Flegrei caldera.

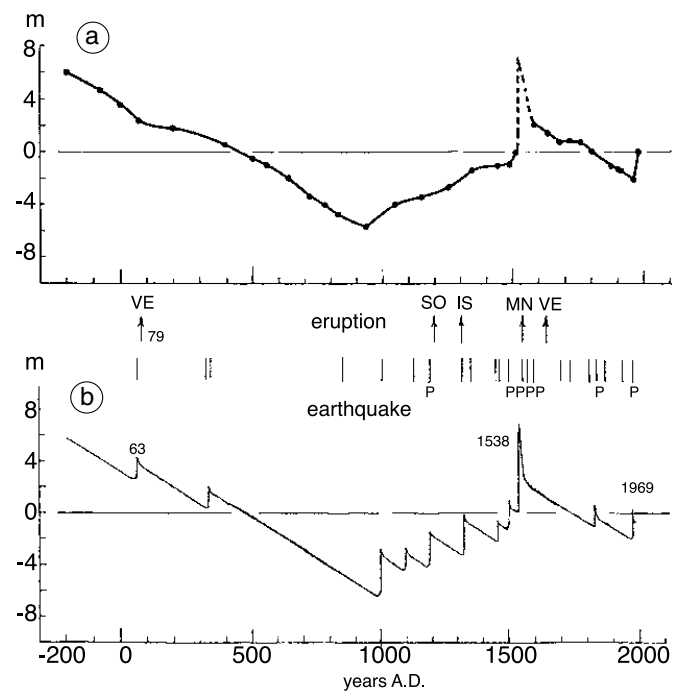

Fig. 2a,b. Deformation trends of Serapeo proposed by (a) Parascandola (1947) and (b) Casertano et al. (1976). Eruptions: arrows indicate major local eruptions probably capable to effect Pozzuoli (VE: Vesuvius; SO: Solfatara; IS: Ischia; MN: Monte Nuovo). Earthquakes: bars indicate major earthquakes in Campania, and bars with letter P do earthquakes in the Pozzuoli area.
After 1969, the precise levels have been repeated around Pozzuoli. Oliveri del Castillo and Quagliariello (1969) found that Pozzuoli had uplifted approximately $94 \mathrm{~cm}$ since 1953, by mareographic observations on February 5, 1970. The upheaval probably began in 1969 . On this assumption, it may have continued to sub-side for 16 years from 1953 to 1969 . If we assume that Pozzuoli subsided $22 \mathrm{~cm}(=1.4 \mathrm{~cm} / \mathrm{yr} \times 16 \mathrm{yr})$ from 1953 to 1969 , we may conclude that it had uplifted $116 \mathrm{~cm}(=94 \mathrm{~cm}+22 \mathrm{~cm})$ over a period of nearly 4 months; the rate is approximately $3.5 \mathrm{~m} / \mathrm{yr}$. Since the end of February 1970, a seismometric network has been installed in Campi Flegrei. Berrino and Corrado (1991) and Berrino (1998) discussed the sea-level changes and the temporal trends of seismicity at Pozzuoli during the period 1970 1995 as shown in fig. 3 where the deformation curve has roughly similar trend to that of the seismicity diagram. This means qualitatively that the volume changes were accomodated by seismic failure. In the figure, there are two peaks on both trends, in 1973 and 1984. During 1970 1973, both deformation and seismicity were rather low: a few microearthquakes of magnitude $M 0 \sim 2$ were registered every day, and Pozzuoli uplifted approximately $70 \mathrm{~cm}$ in total. This was a measurable ground deformation with low seismicity. During 1983 1984, the activities increased remarkably. According to Dvorak and Gasparini (1991), on May 15, 1983, an earthquake of $M 3.4$ took place, and was followed by shallow earthquake swarms for 15 months. The largest earthquake of $M 4.2$ occurred on October 4, 1983. Considering the high upheaval rate at Pozzuoli, amounting to $1.5 \mathrm{~m} /$ $2 \mathrm{yr}$, we may say that seismic efficiency for the period was low. Later in the paper, «seismic efficiency» will be discussed to compare energies of earthquakes with energy of ground deformation.

Seismicity and deformation - As for the relationship between volcanic earthquakes and associated deformations, we know the following example of the 1977 eruption of Usu volcano, Japan. Yokoyama et al. (1981) found that the rate of seismic energy release is proportional to the rate of deformation (upheaval rate) as shown in fig. 4. This relationship is approximately valid 


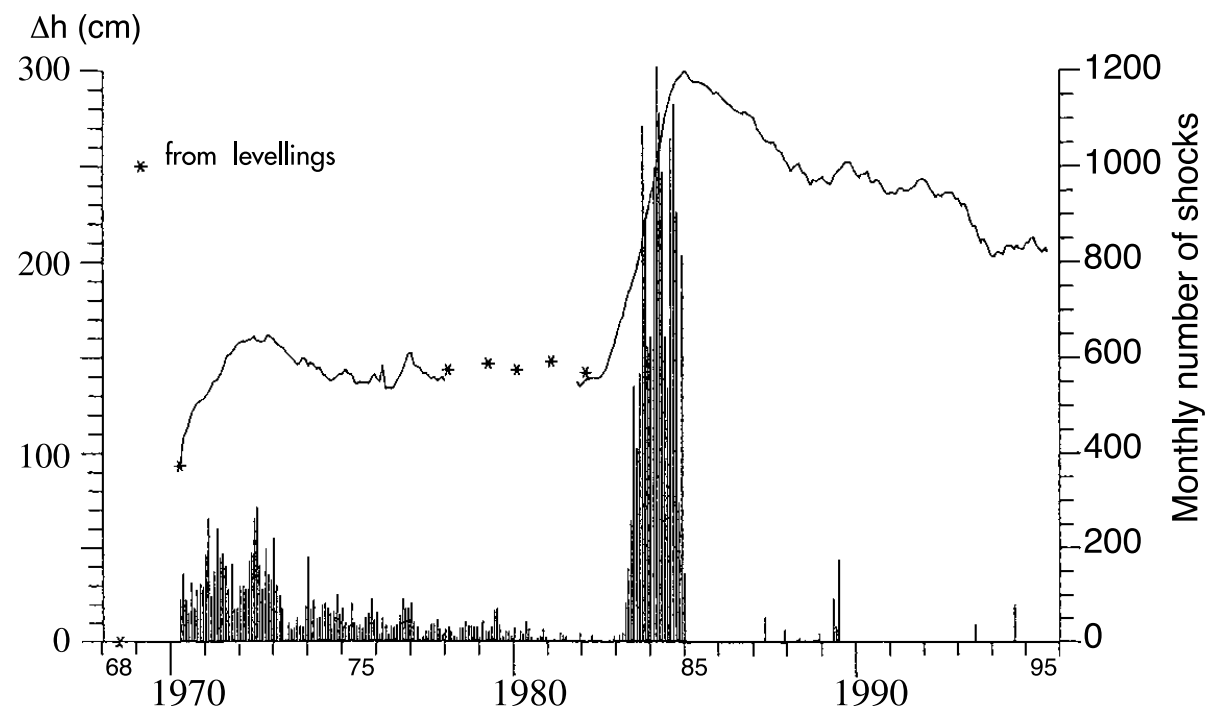

Fig. 3. Seismicity (monthly numbers of shocks) and uplifts $(\mathrm{cm}$ ) at Pozzuoli during the period 1970 1995 (after Berrino, 1998).
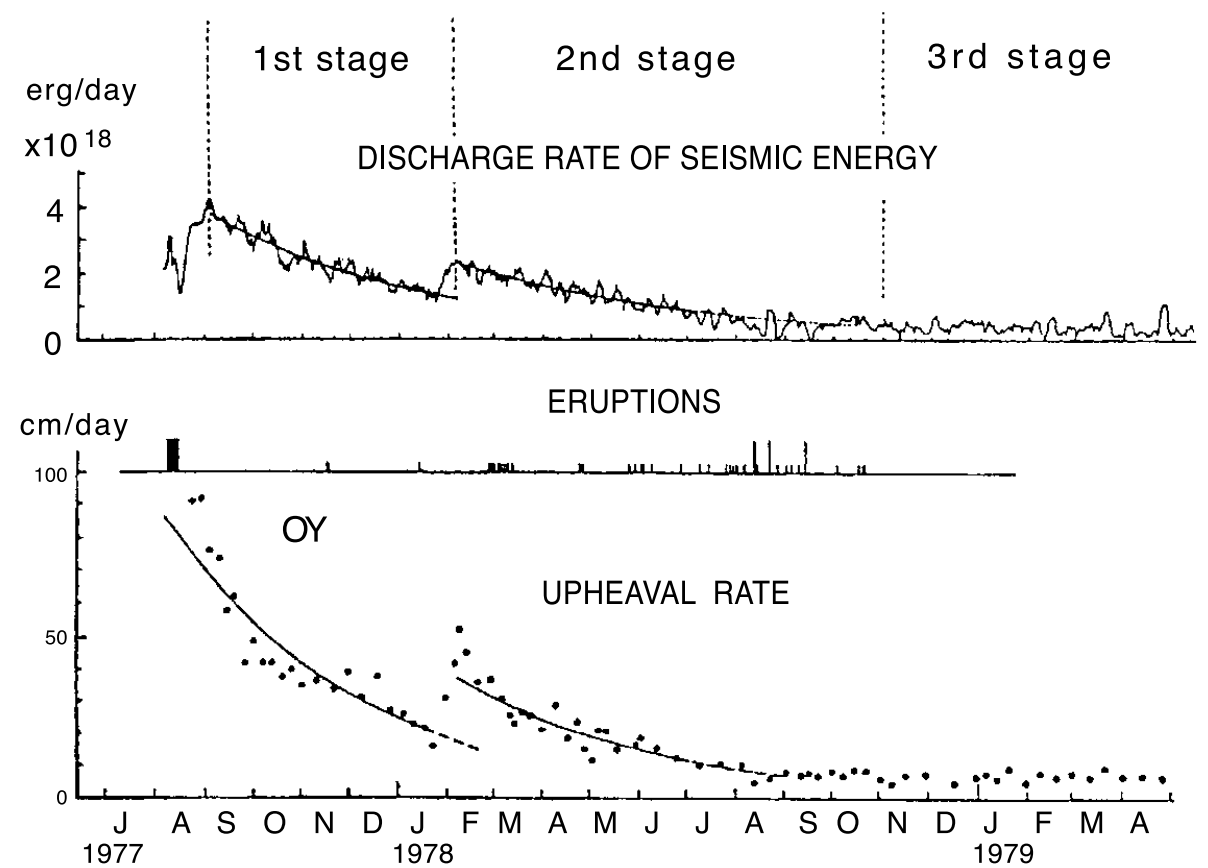

Fig. 4. Seismicity and deformation in the 1977 eruption of Usu volcano, Hokkaido (after Yokoyama et al., 1981). Daily discharge rate of seismic energy (erg/day) averaged for every 5 days, and daily upheaval rate $(\mathrm{cm} /$ day) of the summit dome averaged around observation periods. Eruption magnitudes are shown in arbitrary scale. 
for the Pozzuoli event as seen in fig. 3 where, strictly speaking, the number of shocks must be converted into energy releases. It is remarkable that the Pozzuoli event covering 20 years exhibits the same characteristics as the 1977 Usu eruption accompanied with severe explosions covering 2 years. In fig. 3 , the subsidence after 1985 was accompanied with very few earthquakes. This means that the recovery was not by elastic rebound, but rather by rheologic flow. In other words, Serapeo tends to subside without any local shocks to disturb the Pozzuoli area. Local earthquakes originating at the Pozzuoli area should be accompanied by local deformation provided that the deformation is caused by seismic failure. Reports of felt shocks at Pozzuoli in the historical documents suggest that these shocks may have been accompanied by some movement at Pozzuoli. Dvorak and Gasparini (1991, table 1) examined reliable data of local felt earthquakes around Pozzuoli after the 15th century. They mentioned 8 felt shocks in the 16th century after the 1538 eruption of Monte Nuovo, and no felt shocks in the 17 th and 18th centuries. These felt shocks may have disturbed the ground level at Serapeo. Dvorak and Gasparini (1991) concluded that no remarkable movements have occurred at Pozzuoli during approximately 300 years after 1538 . During that period, Serapeo may have subsided smoothly and rheologically.

Seismic efficiency - To examine quantitatively the relationship between seismicity and corresponding deformation, seismic efficiency shall be considered. Seismic efficiency $\eta$ is defined as ratios of the elastic energy radiated seismically and the energy required for volumetric changes (McGarr, 1976) where the volume changes are conditionally accomodated by seismic failure only. The latter is expressed as

$$
\sigma \cdot|\Delta V|
$$

where $\sigma$ is overburden stress at the hypocentral region, and $|\Delta V|$, volumetric change. Then we get

$$
\eta=\sum E s / \sigma \cdot|\Delta V|
$$

where Es denotes seismic energy. McGarr (1976) determined seismic efficiencies ranged from 0.25 to $3 \%$ for his sampling. For instance, $0.3 \%$ to $3 \%$ for the Denver earthquakes from 1962 through 1967, and roughly $1 \%$ for the Matsushiro earthquake swarms between March and September 1966.

Seismic efficiency of volcanic earthquakes The 1977 eruption of Usu volcano shall be used as an example in the following: its seismicity was high and its deformation was remarkable, both being quantitatively monitored (Yokoyama and Seino, 2000). The summit part of the volcano had uplifted approximately $160 \mathrm{~m}$ and tilted 11 degrees of arc by upward pressure of the intruded magma during the period 1977-1979. Volcanic earthquakes were closely related to ground deformations as already shown in fig. 4 . The total seismic energy released for the 2 years is estimated at $8.5 \times 10^{13} \mathrm{~J}$, and the largest earthquakes were $M 4$. The volume of the upheaval during the 2 years is estimated at $1.2 \times 10^{8} \mathrm{~m}^{3}$. The overburden stress is calculated as $5 \times 10^{7} \mathrm{~Pa}$ assuming the mean depth of hypocenters to be $2 \mathrm{~km}$. Then we obtain $\eta_{\mathrm{Usu}}=1.4 \%$ or roughly $1 \%$.

The magma of the recent activity of Usu volcano is dacitic: under the same temperature, dacitic magma is more viscous than basaltic and andesitic magma. The latter magmas scarcely cause remarkable deformations in comparison with the former. Hence, the seismic efficiencies of earthquakes accompanied with activities of basaltic and andesitic volcanoes must be comparable to $\eta_{\text {Usu }}$ or larger.

Seismic efficiency of the Pozzuoli earthquakes Yokoyama (1988) calculated the seismic efficiency of the 1982-1984 activity of Campi Flegrei. The results for the three periods of 1983 are reproduced in table I (data after Osservatorio Vesuviano, 1984) where $\eta_{\mathrm{Poz}}$ ranges from $10^{-3}$ to $10^{-2} \%$. These are extremely small comparing with tectonic earthquakes and dacitic volcanic earthquakes. During the periods, several earthquakes of $M 3 \sim 4$ occurred, but the seismic efficiency remained low. This is because the caldera deposits are porous and contain much water, and behave anelastically under magmatic actions. 
Table I. Seismic efficiencies of the activities of Pozzuoli and Iwojima.

\begin{tabular}{|c|c|c|c|c|c|}
\hline Locality & Period & $\begin{array}{l}\text { Seismic } \\
\text { energy } \\
\left(\times 10^{10} \mathrm{~J}\right)\end{array}$ & $\begin{array}{l}\text { Volume } \\
\text { change } \\
\left(\times 10^{7} \mathrm{~m}^{3}\right)\end{array}$ & $\begin{array}{c}\text { Elastic } \\
\text { work } \\
\left(\times 10^{14} \mathrm{~J}\right)\end{array}$ & $\begin{array}{l}\text { Seismic } \\
\text { efficiency } \\
(\%)\end{array}$ \\
\hline \multirow{4}{*}{ Pozzuoli* } & 1983 & & & & \\
\hline & Jan.-June & 0.95 & 1.4 & 7.3 & $10^{-3}$ \\
\hline & June-Sept. & 2.7 & 0.4 & 2.1 & $10^{-2}$ \\
\hline & Sept.-Dec. & 15 (incl. $M 4.2$ ) & 2.6 & 1.4 & $10^{-2}$ \\
\hline Iwojima & 1976-1984 & 2.3 & 0.7 & 3.4 & $10^{-2}$ \\
\hline
\end{tabular}

* Data after Osservatorio Vesuviano (1984).

\subsection{Interpretations of the Pozzuoli event}

Already in the previous part, we saw that Serapeo tends to subside and sometimes instantly changes to uplift effected by local volcanic and seismic activities. It is clear that the anomalous deformations at Pozzuoli derive mainly from physical properties of the medium and partly from particular external actions. As mentioned above, Fedi et al. (1991) discussed the subsurface structure of the Pozzuoli area from consideration of gravity data, and showed that the low density materials $\left(\Delta \rho=-200 \mathrm{~kg} / \mathrm{m}^{3}\right)$ are deposited to a depth of approximately $2 \mathrm{~km}$ at the center of Campi Flegrei caldera, of which the southern half is Pozzuoli Bay.

Oliveri del Castillo and Quagliariello (1969) proposed an idea, prior to their finding the rise of Serapeo in February 1970, that Serapeo would have a tendency to subside monotonously due to self-loading compaction of the caldera fills, and that it would turn to uplift instantly when major local earthquakes occurred such as in $63,1488,1536-1538$, and so on, and also when the major eruptions broke out such as Vesuvio (79 and 1631), Solfatara (1198), Ischia (1301) and Monte Nuovo (1538). The above compaction model can account for the variation of subsiding velocity from the borders to the center. Furthermore, Casertano et al. (1976) discussed hydrodynamics and geodynamics in Campi Flegrei and emphasized effects of the sea movement. They modified Parascandola's diagram as shown in fig. 2b. In this diagram, the height of Serapeo increased instantly with a high rate when triggered by major local shocks or nearby volcanic activities, and recovered rheologically.

As discussed above, during the Pozzuoli event, seismic efficiency was extremely low: this means that the medium is anelastic and deforms by self-loading compaction. When magmatic forces act at the caldera or local earthquakes disturb it, the medium changes to reverse almost instantaneously with a large deformation, and when the external factors stop, the medium resumes subsiding rheologically.

Around the caldera of Campi Flegrei, there are post-caldera volcanoes such as Monte Gauro, Solfatara and Monte Nuovo. It may be probable that the magma remains beneath the Pozzuoli area although it is probably not so large.

\section{Iwojima}

Iwojima is located at $1200 \mathrm{~km}$ south of Tokyo, in the north-west Pacific Ocean and belongs to «Volcano Islands» (fig. 5). «Iwo» means sulfur and «jima» (or shima) island. «Sulfur island» means an island of many fumaroles. It is the largest of the Volcano Islands, measuring approximately $8 \mathrm{~km}$ in the NE direction and occupying approximately $20 \mathrm{~km}^{2}$ in area.

The English exploration ship «Resolution» visited there in 1779. The oldest sketch and description of Iwojima can be found in the report 


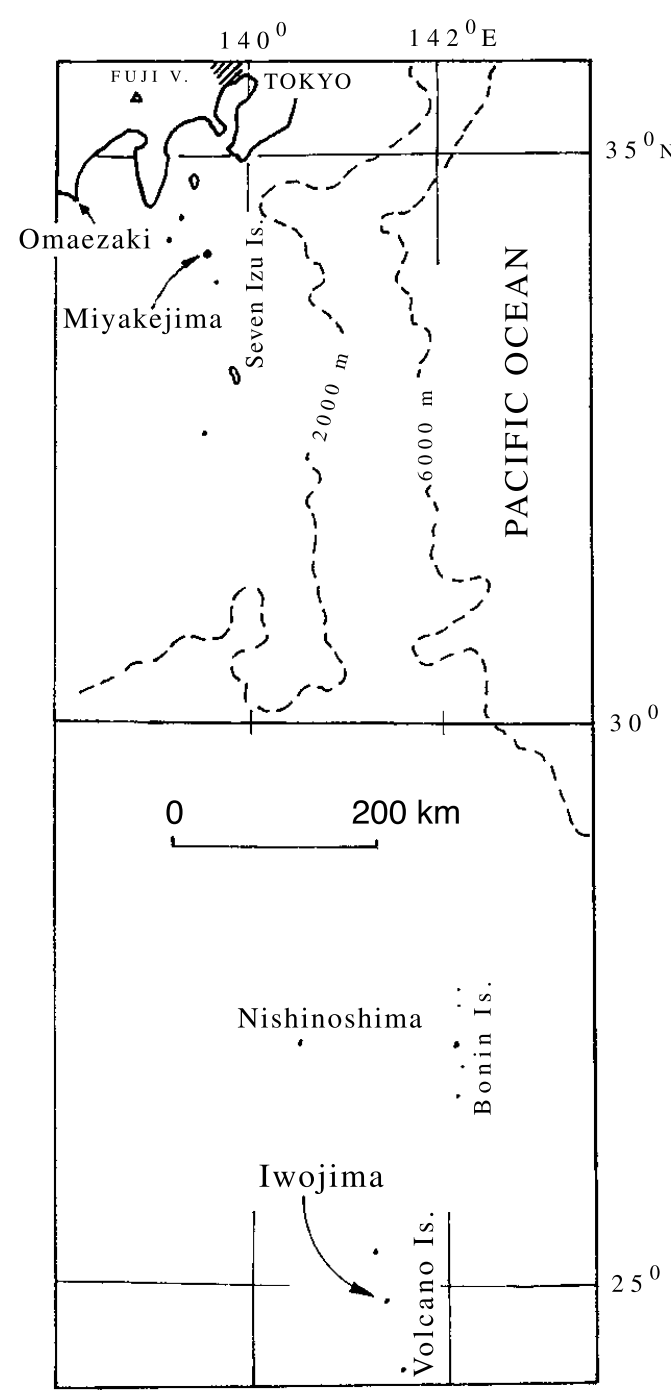

Fig. 5. Location map of Iwojima, Miyakejima and Cape Omaezaki.

of King (1785): «The shoreline where Captain Cook's surviving crews landed in 1779 is now approximately $40 \mathrm{~m}$ above sea level». Its secular upheavals were first studied in 1925 and monitored intensively after 1952. A special issue of Journal of Geography, vol. 94 (1985, Eds. J. Ossaka, H. Takahashi and S. Kaizuka) including
18 papers (in Japanese with English abstract) was devoted to earth science studies of Iwojima, especially anomalous deformations. Recently modern techniques, such as GPS and SAR, are being applied to this anomalous deformations. Our discussion mainly depends on the data published in these papers.

\subsection{Geologic setting of Iwojima}

Iwojima is the summit part of a large volcano standing from the sea bottom of $1 \sim 2 \mathrm{~km}$ deep and measuring approximately $40 \mathrm{~km}$ in basal diameter. The surrounding submarine bathymetry shows a caldera-like topography measuring approximately $10 \mathrm{~km}$ in diameter and the caldera rims are just submerged beneath the sea. The northern half of the island is the central cone. A geologic sketch map is shown in fig. 6, after Morimoto et al. (1968). The island consists of three parts: 1) Motoyama (MO, $115 \mathrm{~m}$ a.s.l.) in the NE part is not a constructional cone but a structural uplift, and is composed of alternating of tuff breccia and lava beds, both of which consist of trachyte andesite. This volcano was

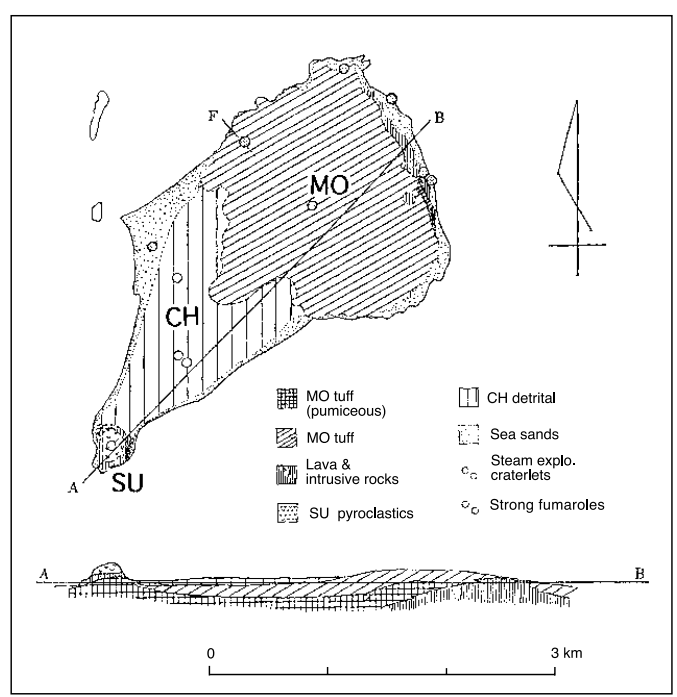

Fig. 6. Geologic sketch map of Iwojima (after Morimoto et al., 1968). 
built mainly under the sea, and later was thrust up above the sea level. 2) Suribachiyama (SU, $167 \mathrm{~m}$ ) at the SW end, is a scoria cone with a crater, under which lie lava flows and pyroclastic deposits. All these rocks are also trachyte andesite. 3) Chidorigahara ( $\mathrm{CH})$, an unconsolidated sandy isthmus connecting the two parts, was built by pyroclastic deposition combined with uplift. A residual low gravity anomaly of approximately 7 mgal centers on the $\mathrm{CH}$ area. This suggests a thick accumulation of porous volcanic clastics below.

\subsection{Ground deformation and seismicity on Iwojima}

Ground deformation - The first topographic survey of this island was carried out in 1911 and a topographic map of $1 / 50000$ in scale was published. Homma (1925) examined the geology of this island, and noticed its remarkable uplift. Topographic surveys were repeated in 1944, 1948, 1952, 1968 and 1979, and the maps have been revised. In the 1960s, the receding of the shoreline drew the attention of earth scientists as evidence of the unusual uplift of the island.

Secular uplift of the island since the 18th century is shown in fig. 7a,b after Kaizuka et al. (1985) where (a)-lines show the change in height above sea level of the lowest point at the isthmus at the northern foot of SU and the 1779 value is deduced from the sketch and the description by King (1785). b)-Line shows the accumulated uplift of the same point obtained by instrumental surveys since 1911. From these two curves, we may say that the average uplift rate is approximately $20 \mathrm{~cm} / \mathrm{yr}$ through the last 2 centuries.

The distribution of the uplift during 16 years from 1952 to 1968 obtained by Tsuji et al. (1969) using geodetic means is shown in fig. 8a. In the figure, the uplift increases towards the NE, and the $\mathrm{CH}$ area locally uplifted $7 \mathrm{~m}$. Kumagai and Takahashi (1985) observed the deformation during the period 1976 1984 amounting to approximately $2 \mathrm{~m}$ uplifts at the $\mathrm{CH}$ and the $\mathrm{MO}$ areas. In short, Iwojima as a whole island, has continued to rise. However, on the island, the center of uplift and that of subsidence may have migrated between the two areas. This means that movement of the whole island is controlled by a deeper magmatic force that is rather stable, on which is superimposed a shallower source whose position varies with time.

The ground surveys on Iwojima are based on mareographic observations which are not always easy to make. Because of this, remote sensing techniques were found useful. Ohkura (1998) analyzed interferometric SAR images of Iwojima obtained in 1993 and 1995, and found a concentric zone of subsidence at the MO area that agrees with the result of precise levels during the same period shown in fig. $8 \mathrm{~b}$.

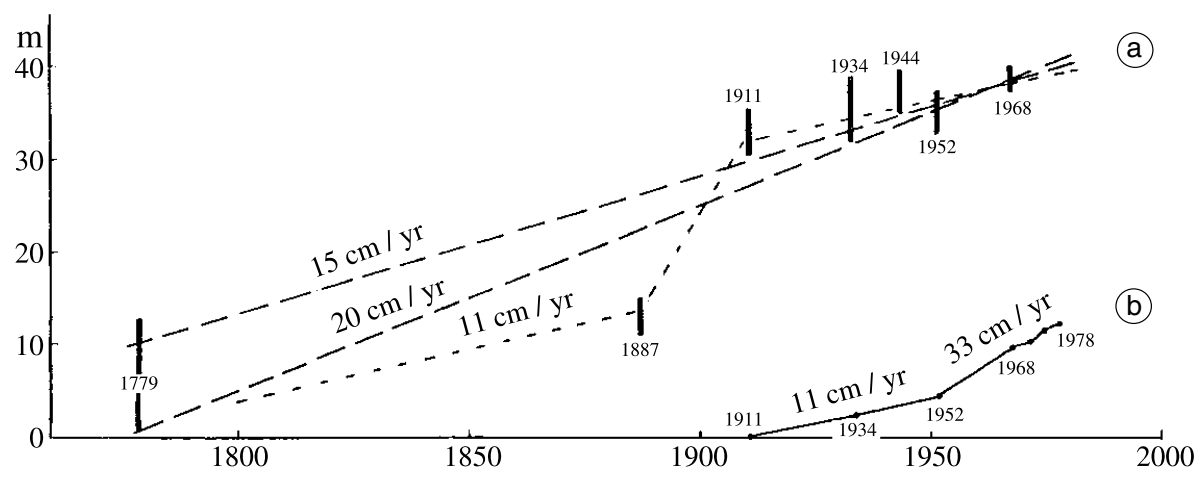

Fig. 7a,b. Secular movements of Iwojima (after Kaizuka et al., 1985). a) Secular change in height (above sea level) of the isthmus at the north of SU; b) Accumulated uplift and annual rates after 1911. 

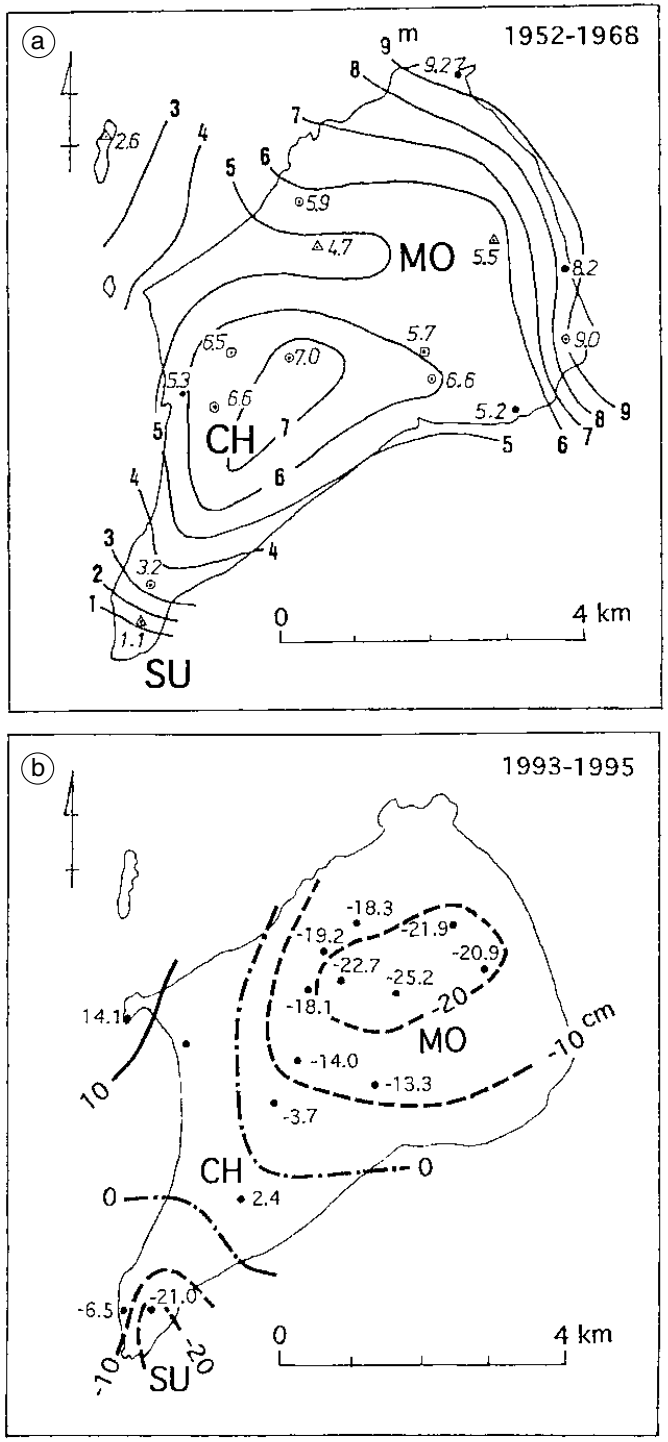

Fig. 8a,b. Crustal movements at Iwojima. a) Uplift (m) during the period 1952 1968 obtained by geodetic methods (after Tsuji et al., 1969); b) Deformation (cm) during the period 1993 1995 obtained by precise levels. This is comparable with the result obtained by interferometric SAR images (after Ohkura, 1998).

Volcanic activity - There are many solfatara, steam fumaroles, hot springs and hot grounds whose temperature is approximately $100^{\circ} \mathrm{C}$.
Since 1890, more than 15 steam explosions have occurred at several fumaroles on the island although they were not very explosive. Around Iwojima, there occurred several submarine eruptions in the 20th century: a submarine eruption occurred at a distance of $5 \mathrm{~km}$ NNE of the island in 1904, and again in 1914, and eruptions also occurred near the same sea area in 1937 and 1968. In 1973, a submarine eruption began quite near Nishinoshima (fig. 5) located at approximately $260 \mathrm{~km} \mathrm{~N}$ of Iwojima, and a new island was formed.

On and around Iwojima, small eruptions have occasionally broken out. On September 21, 2001, a small submarine eruption occurred at the NW part of the island, $1 \mathrm{~km}$ off Iwojima: sea water in a circle $10 \sim 15 \mathrm{~m}$ in diameter gushed up to a height of about $5 \mathrm{~m}$ and it continued for $1 \mathrm{~h}$. On the island, about 20 microearthquakes were observed on that day.

Seismicity - Iwojima has shown rather low seismicity in spite of the remarkable deformation and intensive fumarolic activity. Monitoring of earthquakes with 5 seismometers on this island were begun in 1976 (Kumagai, 1985). Monthly means of daily numbers of volcanic earthquakes observed on the island are shown in fig. 9 where the arrows with numbers represent steam explosions counted since 1890 . Felt shocks $(M \geq 2)$ were observed once in March 1980 and 13 in November 1982. The latter accompanied the 15th explosion. The steam explosions were accompanied by several earthquakes every day, and small swarms (up to 40 events per day) every few months. Their hypocenters were dispersed beneath the entire island, at depths between 0 and $4 \mathrm{~km}$. Their magnitudes ranged from 0 to 2 . Felt shocks had not been reported until November 1982 when an earthquake swarm with felt shocks continued for 6 days.

Seismic efficiency - During the period March 1976 to February 1984, both deformation and seismicity data are available (Kumagai, 1985). The uplift amounted to $2.0 \mathrm{~m}$ at the $\mathrm{CH}$ area (fig. 6) during the period: the volume change is roughly estimated at $7 \times 10^{6} \mathrm{~m}^{3}$. During the same period, there were approximately 10880 unfelt earthquakes $(M \leq 1)$. The total seismic energy 


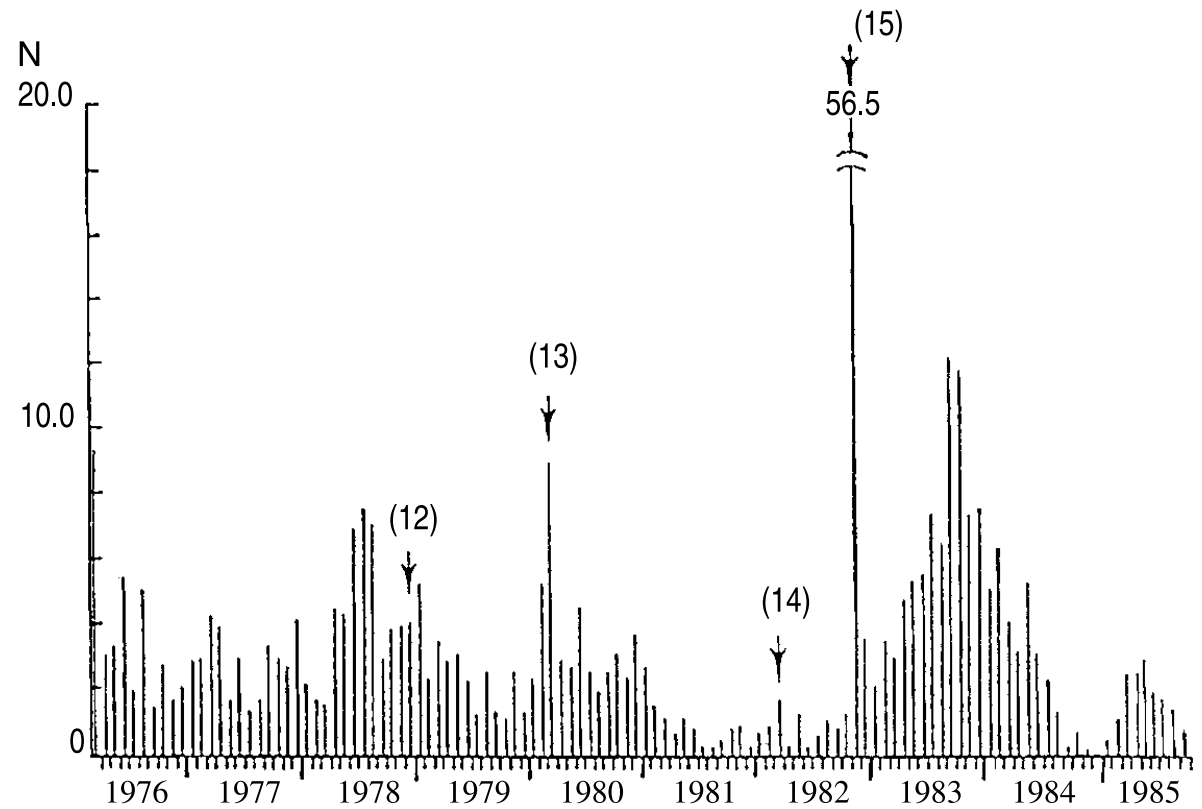

Fig. 9. Monthly mean of daily frequency of volcanic earthquakes at Iwojima, observed for the period 1976 1985 (after Kumagai, 1985). Arrows indicate steam explosions counted since 1890.

release during the period is roughly estimated at $2 \times 10^{10} \mathrm{~J}$. The hypocenters were distributed at depths from the surface to $4 \mathrm{~km}$ : the overburden stress is calculated as $5 \times 10^{7} \mathrm{~Pa}$ assuming the mean depth of the hypocenters to be $2 \mathrm{~km}$. The seismic efficiency during the period is estimated at $\eta_{\text {Iwo }}=10^{-2} \%$ (table I). This is extremely small and of the same order of magnitude as that of Campi Flegrei.

\subsection{Origin of anomalous upheavals on Iwojima}

Iwojima originally formed as the central cone of a submarine caldera, and is composed of pyroclastic material. During the past 2 centuries, the island as a whole has continued to rise due to intrusion of magmatic material, causing intermittent steam explosions and fumarolic activity. As mentioned above, two magmatic forces, deeper and shallower, are assumed to control the deformation of the whole island and local surface changes, respectively.
Considering the frequent submarine eruptions in the surrounding sea and the 1973 eruption of Nishinoshima (fig. 5) in addition to sporadic volcanic and seismic activities and remarkable ground movements on the island, we may say that the volcanic energy source around Iwojima is enough reserved to maintain the present state for some time into the future.

\section{Secular ground deformations with low seismicity; volcanic and tectonic examples in Japan}

Aira caldera, Kyushu-Aira caldera, Kyushu is approximately $20 \mathrm{~km}$ in diameter and a postcaldera volcano, Sakurajima stands at the southern rim of the caldera (fig. 10a). The subsurface structure of Aira caldera is discussed by Yokoyama and Ohkawa (1986). In 1914, Sakurajima violently erupted effusing andesitic lava of $1.4 \mathrm{~km}^{3}$ in dense rock equivalent. During the eruption, a large earthquake of $M 7.1$ occur- 
red near the volcano (Omori, 1914-1922). The precise levels around the caldera have been repeated since 1891. The secular height changes of a benchmark (BM 2474) at the western rim is shown in fig. 10b (Yokoyama, 1986). It subsided approximately $75 \mathrm{~cm}$ almost simultaneously with the 1914 eruption, and additive $5 \mathrm{~cm}$ viscoelastically in the following 7 months. Thereafter it gradually recovered for roughly 70 years without much earthquake activity. Yokoyama (1996) interpreted the recovery from the standpoint of rheology of the crust beneath Sakurajima. If we adopt a model of a Kelvin solid, retardation time of a recovery process is given by $\mu / k$ where $\mu$ denotes viscosity and $k$ bulk
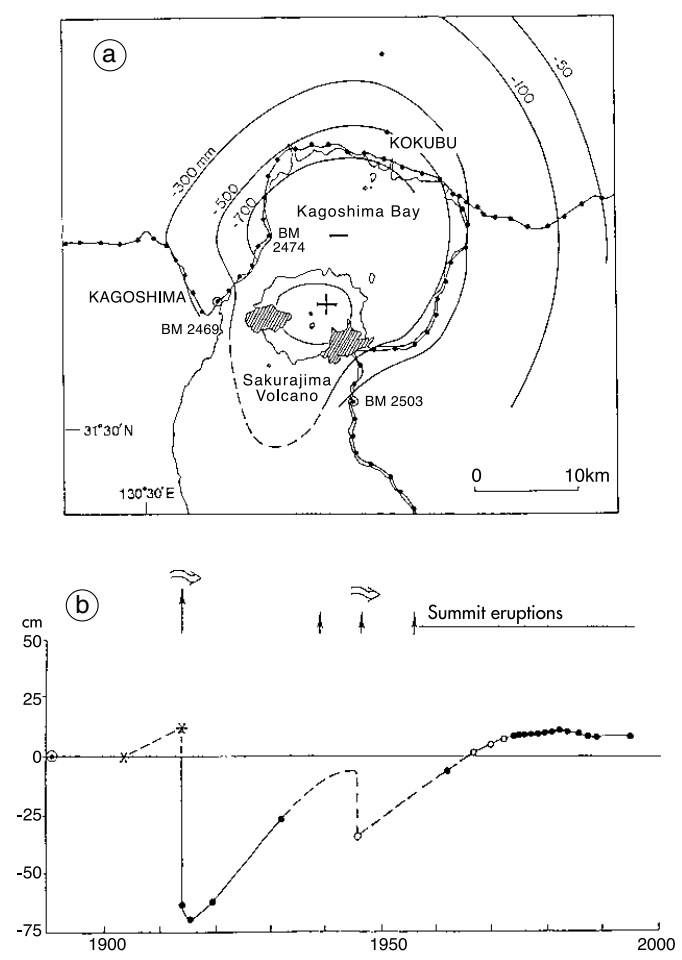

Fig. 10a,b. Aira caldera. a) The subsidence (mm) caused by the 1914 eruption of Sakurajima volcano, the hatched parts indicate the new lava flows (after Omori, 1914-1922). b) Secular deformation of BM 2474 referred to BM 2469. The asterisks show the interpolation (data after Sakurajima Volcano Observatory). modulus. In fig. 10b, after the 1914 eruption, the retardation time is roughly estimated at 22 years. When we adopt $k$ conventionally as $30 \mathrm{GPa}$, the viscosity of the medium $\mu$ is calculated to be $2.1 \times 10^{19} \mathrm{~Pa} \cdot \mathrm{s}$. This may be plausible, granting the uncertainty of the $k$ value.

When we compare fig. $10 \mathrm{~b}$ with fig. $2 \mathrm{~b}$ for Serapeo, we notice that both the deformations derive from rheological property of the media; the crust beneath Aira caldera and the caldera fills in Pozzuoli. On the other hand, the controlling forces are different; upward restoring force of the crust after instantaneous subsidence in the former, and downward compaction after instantaneous uplifts in the latter.

Miyakejima, Seven Izu Islands - Miyakejima is a basaltic volcano island at approximately 170 km south of Tokyo (figs. 5 and 11a). In the 1983 eruption of the volcano, a benchmark used for precise levels (BM 10250) near the explosion site rose instantaneously approximately $17 \mathrm{~cm}$ as shown in fig. 11b. After the eruption, it recovered without any noticeable seismic activity. The retardation time is determined as approximately 9 years. The viscosity of the upper crust of Miyakejima volcano is approximately $8.6 \times 10^{18}$ $\mathrm{Pa} \cdot \mathrm{s}$ which is a little smaller than that of Aira caldera. If the difference of the viscosity is meaningful, it may be controlled by differences in the depth of deformation volume. Figure 11b indicates that the 1983 deformation at that benchmark has not totally recovered as of 1997 , and it may be permanently deformed.

In June 2000, the volcano reawoke at the summit crater, and in September, the crater bottom collapsed approximately $300 \mathrm{~m}$. During that event, deformations of the benchmarks along the coast were not noticeable.

Cape Omaezaki, Tokai - Cape Omaezaki is located along the Pacific coast of the Tokai district (fig. 5) and lies within a potentially hazardous area related to a Tokai earthquake that is believed to be imminent and should be of $M 8.4$ class. This region is non-volcanic and lies above the subduction of the Philippine Sea plate beneath the Eurasian plate. Cape Omaezaki at the edge of the Eurasian plate is dragged downward and gradually subsides until another large earthquake 

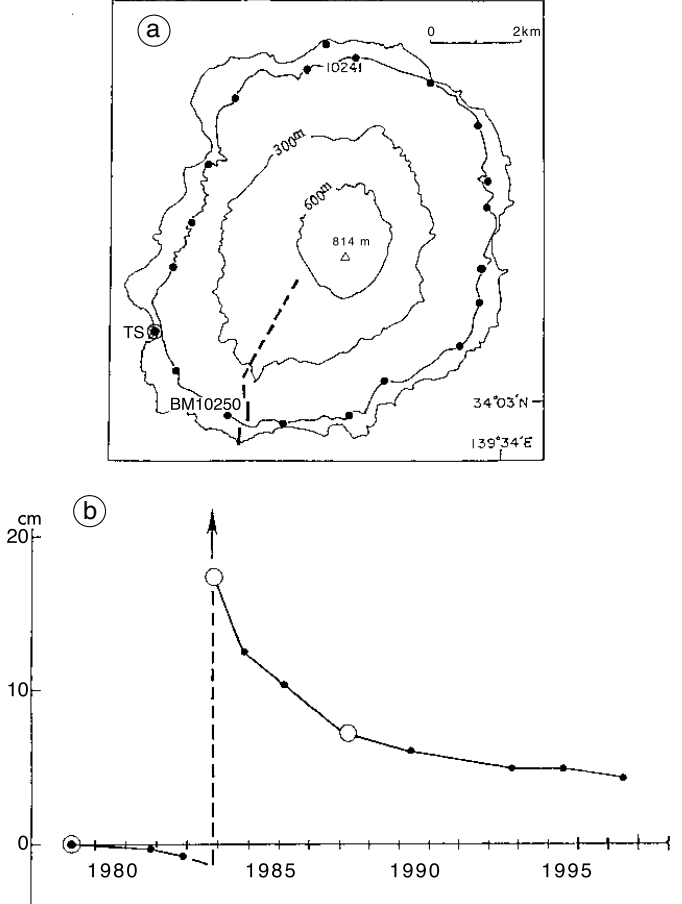

Fig. 11a,b. Miyakejima. a) Distribution of the benchmarks for the precise levels along the shore. A broken line indicates the line of the 1983 fissure eruption; b) Vertical deformation $(\mathrm{cm})$ of a benchmark near the explosion site (BM 10250) referred to the tide gauge station (TS). The arrow indicates the eruption and the hollow circles interpolated values (after Yokoyama, 1996). occurs. In this region, the last earthquake of $M$ 8.4 took place in 1854 and since then, no large earthquakes have occurred. Precise levels have been carried out since 1962 to monitor the activity of this area. The cape has subsided secularly approximately $20 \mathrm{~cm}$ during the period 1962 to 2000 and the subsidence is believed to be a precursor of a large subduction earthquake. Through all the period, no microearthquakes have been observed in this region. The deformations extend to a distance of approximately $100 \mathrm{~km}$ from the cape.

The secular changes in height of BM 2595 (near Cape Omaezaki) as referred to BM 140-1 (Kakegawa) are shown in fig. 12 (Geographical Survey Institute, 2001) where the surveys repeated four times every year after 1980, revealed the annual changes. The origin of the annual changes is not clear at present. The distance between the two benchmarks is approximately $20 \mathrm{~km}$. Cape Omaezaki has continued to subside at a rate of approximately $0.5 \mathrm{~cm} / \mathrm{yr}$. The subsidence is gradual, but could be a significant precursor of the Tokai earthquake.

\section{Concluding remarks: characteristics of various secular deformations with low seismicity}

In the above, we reviewed the examples of secular gradual deformations in both volcanic and tectonic areas; they have individual char-

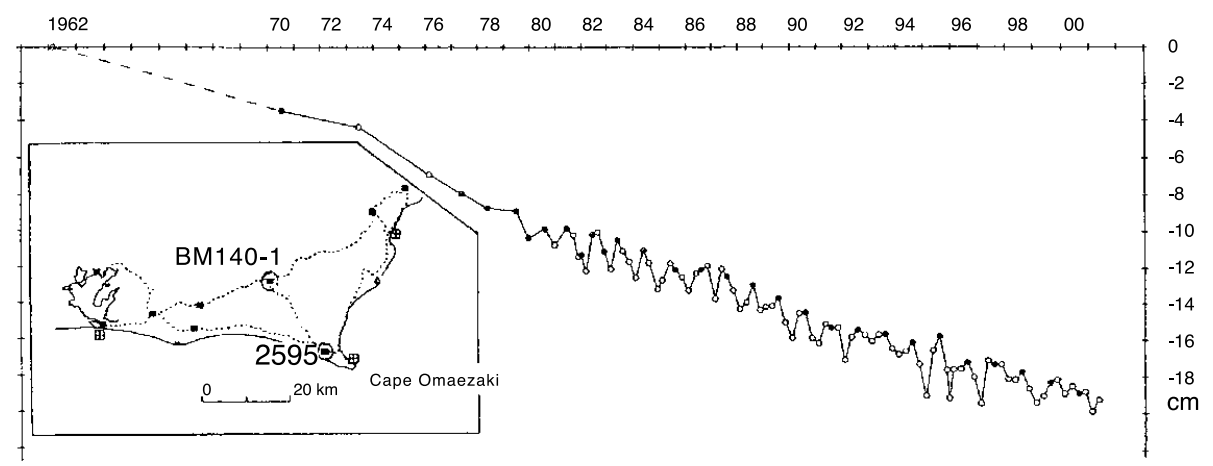

Fig. 12. Secular deformation of Cape Omaezaki since 1962 (after Geographical Survey Institute, 2001). 
acteristics controlled by the nature of the local crust, and by the local sources of stress.

Tectonic settings - The majority of secular gradual deformations are observed in volcanic areas, particularly in caldera regions: Pozzuoli is located at the center of Campi Flegrei caldera, and Iwojima is also the center of a submarine caldera. Aira caldera contains an active postcaldera volcano, Sakurajima. These calderas are characterized by low gravity anomalies which originate from thick deposition of coarse pyroclastic material. Such materials behave anelastically against external forces in both the short- or long-term. Miyakejima is a volcano island and may have a particular basement structure which reacts anelastically to magmatic intrusions.

The phenomena rarely occur in tectonic areas: an example is near a subduction zone. Cape Omaezaki is located along the Pacific Ocean and over the subducting Pacific plate.

Geodynamic forces - The secular subsidence of Pozzuoli may be interpreted by self-loading compaction of the caldera deposits and sometimes has been reversed in the short-term by local earthquakes of magmatic origin or major volcanic eruptions.

Iwojima, as a whole, has risen continuously due to a deep magmatic force, and sometimes shallow magmatic steam pressure effects local deformations.

Secular deformations observed on Aira caldera and Miyakejima are recovery stages of the strains caused by volcanic eruptions; the former is a subsidence and the latter is an uplift.

Omaezaki receives a regional tectonic force which is long-term and should result in an instantaneous breakdown when the crustal strain reaches the elastic limits.

Time constants - The events mentioned in the present paper have the time constants covering a wide range. Pozzuoli had subsided at a rate of $1.4 \mathrm{~cm} / \mathrm{yr}$ after the 1538 eruption of Monte Nuovo and suddenly began to rise at a rate of $3.5 \mathrm{~m} / \mathrm{yr}$ in 1970. If we adopt the model of self-loading compaction, it should finally approach equilibrium asymptotically in several thousands of years.
Iwojima, as a whole, has risen continuously at a rate of $11 \sim 33 \mathrm{~cm} / \mathrm{yr}$ since 1800 with low seismicity. Considering the past volcanic activities on the island and the submarine eruptions in the surrounding sea, we may say that the future activity and deformation on the island would depend on the volume of the remaining magma beneath. The time constant of the Iwojima upheaval may be at least several hundreds of years.

The upheaval around Aira caldera and the subsidence of the 1983 eruption site of Miyakejima both represent recovery of deformation caused by volcanic eruptions. Their time constants are roughly 22 and 9 years, respectively.

The secular subsidence observed at Cape Omaezaki is an example of tectonic ground deformation or a precursory of a large subduction earthquake. The cape subsides gradually with very low seismicity due to subduction of the Pacific plate. Its subsidence rate since 1962 is $0.5 \mathrm{~cm} / \mathrm{yr}$, the smallest rate of the many events mentioned in this paper. Such subsidence may have continued since the last Tokai earthquake in 1853, and should rebound instantly by release of the strain energy as a large earthquake. The recurrence time of the Tokai earthquake may be around 150 200 years.

In conclusion, the characteristics of anomalous crustal movements with low seismic efficiency derive from two factors: one is the property of the medium, with the exception of Omaezaki where the crust is not involved, and the other is geodynamic forces acting on respective site. The crust is a complicated medium, particularly in volcanic area, and responds in various ways to various geodynamic forces, short-term and long-term.

\section{Acknowledgements}

The authors are grateful to Prof. A. Rapolla for his critical discussion on the Pozzuoli event. The useful information on the recent state of Iwojima were afforded to us by Dr. M. Ukawa, to whom our thanks are extended. We extend our gratitude to Dr. R. Azzaro for his critical review of the manuscript. We appreciate the assistance of Dr. Thomas L. Wright who provided helpful 
suggestions for improvements of the manuscript. We further thank the colleagues of the Osservatorio Vesuviano for their scientific friendship over many years.

\section{REFERENCES}

BERRINO, G. (1998): Detection of vertical ground movements by sea-level changes in the Neapolitan volcanoes, Tectonophysics, 294, 323-332.

BERRINO, G. and G. CoRRADO (1991): Tidal signal in the recent dynamics of Campi Flegrei caldera (Italy), J. Volcanol. Geotherm. Res., 48, 93-101.

Casertano, L., A. Oliveri del Castillo and M.T. QUAGLIARIELLO (1976): Hydrodynamics and geodynamics in the Phlegraean fields area of Italy, Nature, 264, 161-164.

DVORAK, J.J. and P. GASPARINI (1991): History of earthquakes and vertical ground movement in Campi Flegrei caldera, Southern Italy: comparison of precursory events to the A.D. 1538 eruption of Monte Nuovo and activity since 1968, J. Volcanol. Geotherm. Res., 48 , 77-92.

Fedi, M., C. Nunziata and A. Rapolla (1991): The Campania-Campi Flegrei area: a contribution to discern the best structural model from gravity interpretation, J. Volcanol. Geotherm. Res., 48, 51-59.

GeOgRaPhyCAL SURVEY InSTITUTE (2001): Crustal movements in the Tokai district, Rept. Coord. Com. Earthquake Predic., 66, 277-289.

HоммA, F. (1925): A record of geological observation on Iwojima, Chikyu, 4, 290-309 (in Japanese).

KAIZUKA, S., S. KATO, S. NAGAOKA and T. MIYAUCHI (1985): Geomorphology of Iwojima and surrounding sea floor, J. Geogr. 94, 424-436 (in Japanese with English abstract)

KING, J. (1785): A Voyage to the Pacific Ocean, vol. II, pp. 556, 2nd ed., London

KUMAGAI, T. (1985): Volcanism and seismicity in the Iwojima volcanoes, J. Geogr., 94, 455-463 (in Japanese with English abstract).

KUMAgAI, T and H. TAKAHASHI (1985): Crustal deformations on Iwojima (II), J. Geogr., 94, 479-487 (in Japanese with English abstract).

MCGARR, A. (1976): Seismic moments and volume changes, J. Geophys. Res., 81, 1487-1494.

MORimoto, R., J. OsSAKa, T. Hatori, I. IZUTSUya, K.
URABE, H. TAKAHASHI, Y. OKADA, J. HiRABAYASHI, K. ISA and H. ISOBE (1968): The upheaval of an insular volcano Iwojima, Ogasawara Islands and its recent state of activity, J. Geogr., 77, 255-283 (in Japanese with English abstract)

NAZZARO, A. (1985): Il Vesuvio; Storia naturale dal 1631 al 1944, Napoli, Nat. Sci. Bull., 94, 1-26.

OHKURA, H. (1998): Application of SAR data to monitoring earth surface changes and displacement, Adv. Space Res., 21, 485-492.

OLIVERI DEL CASTILLO, A. and M.T. QUAGLIARIELLO (1969): Sulla genesi del bradisismo Flegreo, Atti Ass. Geofis. Ital., $18^{\circ}$ Convegno, $557-594$.

OMORI, F. (1914-1922): The Sakurajima eruption and earthquakes, Bull. Imp. Earthquake Inv. Comm., 8, $1-525$.

OsSeRVATORIO Vesuviano (1984): Bradisismo Flegreo, Rapporto Sorveglianza, Gennaio 1982-Gennaio 1984, Internal Report, Napoli, pp. 93.

Parascandola, A. (1947): I Fenomeni Bradisismici del Serapeo di Pozzuoli, Napoli, pp. 156.

Rosi, M.,A. SBRANA and C. PRINCIPE (1983): The Phlegraean Fields: structural evolution, volcanic history and eruptive mechanism, J. Volcanol. Geotherm. Res., 17, 273-288.

TSUJI, S., M. KURIYAMA and E. TSURUMI (1969): Report of investigations on Bonin Islands, Rep. Geogr. Sur. Inst., 37, 1-18 (in Japanese).

YoKoYAma, I. (1970): Pozzuoli event in 1970, Nature, 229, 532-534.

YoKOYAMA, I. (1986): Crustal deformation caused by the 1914 eruption of Sakurajima volcano, Japan and its secular changes, J. Volcanol. Geotherm. Res., 30, 283-302.

Yokoyama, I. (1988): Seismic energy releases from volcanoes, Bull. Volcanol., 50, 1-13.

YoKOYAMA, I. (1996): Rheological behavior of volcanic deformations, Proc. Jpn. Acad., 72, ser. B, 124-128.

YoKoYAMA, I. and S. OHKAWA (1986): The subsurface structure of the Aira caldera and its vicinity in southern Kyushu, Japan, J. Volcanol. Geotherm. Res., 30, 253-282.

Yokoyama, I. and M. Seino (2000): Geophysical comparison of the three eruption in the 20th century of Usu volcano, Japan, Earth Planets Space, 52, 73-89.

Yokoyama, I., H. Yamashita, H. WATANABE and HM. OKADA (1981): Geophysical characteristics of dacite volcanism. The 1977-1979 eruption of Usu volcano, $J$. Volcanol. Geotherm. Res., 9, 335-358. 